\title{
HERRAMIENTAS PARA EL INVESTIGADOR EN INTERNET
}

Mg. Victor Hugo Terrones Álvarez*

\section{INTRODUCCIÓN}

Durante los últimos 15 años la forma como los investigadores de todo el mundo tienen acceso a la información ha tenido un cambio dramático. El vertiginoso avance tecnológico junto con la globalización de las telecomunicaciones ha permitido que a partir de una red privada de intercambio de información en los años sesenta, se configure lo que hoy conocemos como el Internet.

El diccionario de la Real Academia Española define al Internet como la Red informática mundial, descentralizada, formada por la conexión directa entre computadoras $\mathbf{u}$ ordenadores mediante un protocolo especial de comunicación. Esta definición nos aproxima al criterio de comunicación global, que deriva en un intercambio constante de información a nivel mundial y que proporciona a los investigadores una nueva fuente en su búsqueda de conocimiento: la red de redes.

Pero, ¿cómo pueden aprovechar los investigadores las oportunidades de nuevos conocimientos que brinda el Internet? De una manera muy sencilla: conociendo las herramientas que tienen a su disposición en la web ${ }^{1}$-tales como los motores de búsqueda o los catálogos temáticos- y entrenándose con ellas.
El conocimiento de estas herramientas es un paso fundamental para ingresar en esta nueva era de la información y aprovechar al máximo sus recursos, transformando al elefante blanco que muchos utilizan para actividades triviales en un actor principal para la generación de conocimiento científico.

\section{CONTENIDO}

\section{Los primeros pasos}

Como premisa para realizar una investigación en Internet se debe aceptar que no podemos abarcar toda la información disponible en la red, siendo el cambio la única constante al momento de innovar en herramientas y estrategias de búsqueda.

Asimismo, debemos ser conscientes que no toda la información del Internet es valiosa para los fines de nuestra investigación, por lo que debemos tratarla como susceptible de crítica y de ser cuestionada como cualquier material bibliográfico. El encontrar información valiosa $^{2}$ en la web es una tarea que requiere esfuerzo y una dosis importante de creatividad al momento de utilizar las herramientas que tenemos a nuestra disposición.

* Docente de la Unidad de Postgrado de la Facultad de Ciencias Contables.

1 Web son las siglas de Windows Electronic Bulletin, que hace referencia al contenido que podemos encontrar en el Internet.

2 Mucha información valiosa en Internet se encuentra disponible previo pago de un derecho para acceder a la misma (el denominado sistema «pay per clic»). 
Por último, como en toda investigación sesuda y responsable, el respeto a los derechos de autor es fundamental en la investigación en Internet, debiéndose capturar las direcciones de las páginas web en donde se encontró determinada información, a fin de citarlas como citas bibliográficas ${ }^{3}$ dentro del trabajo de investigación.

\section{La Planificación}

Como en todo proceso de investigación, la planificación es un factor determinante en los resultados finales. En tal sentido, es fundamental "pensar fuera de línea", esto es, identificar la información que se desea obtener mediante la técnica conocida como autoentrevista de referencia. Esta autoentrevista debe responder a las preguntas: ¿cuál es exactamente el tema?, ¿de qué otra manera puedo describir el tema para la búsqueda?, ¿cuál es el objetivo para el cuál se está reuniendo información? $Y$ ¿dónde he buscado ya? Luego de respondidas estas preguntas estaremos listos para el siguiente paso: identificar y aplicar las herramientas específicas a utilizar.

\section{Motores de búsqueda y catálogos temáticos}

El Internet nos brinda una serie de herramientas útiles al momento de buscar información en línea, que funcionan de manera similar a los ficheros de biblioteca tradicionales. Estas herramientas se denominan motores de búsqueda y sirven para encontrar de manera rápida determinada información.

Entre los Motores de Búsqueda más populares ${ }^{4}$ en Internet se encuentran Google (www.google.com), Altavista (www.altavista.com) y Hotbot (www.hotbot.es). Asimismo, un motor de búsqueda peruano bastante utilizado es Yachay (www.yachay.com) el cual agrupa una gran parte de páginas web peruanas.

Cada buscador contiene un universo propio de páginas web en las que realiza la búsqueda, por lo que se recomienda utilizar más de uno. Para lograr este objetivo, es bastante útil emplear los meta motores de búsqueda, ya que ejecutan la consulta en varios motores a la vez.

Entre los meta motores más utilizados se encuentra Dogpile (www.dogpile.com) y Mamma (www.mamma.com), quienes realizan las consultas hasta en veinte motores de búsqueda a la vez.

Sin embargo, si lo que deseamos es realizar una búsqueda que se aproxime a revisar una enciclopedia, es bastante útil revisar los catálogos temáticos disponibles en línea. Estos catálogos organizan la información de acuerdo a cierta estructura -por tópicos o temas generales- a efectos de llegar a temas específicos a partir de temas generales.

Uno de los principales catálogos temáticos es Yahoo (www.yahoo.es) que permite inclusive explorar contenido específico a nivel de país o área geográfica.

3 Al citar direcciones en Internet se debe consignar la siguiente información: Apellidos y Nombres del responsable de la página, título de la página, título de la publicación, nombre del autor de la publicación, año de la publicación en web, dirección electrónica completa y fecha - hora de consulta.

4 Una referencia rápida a los motores de búsqueda más importantes en la web podemos encontrarla en www.searchenginewatch.com 
Páginas de gurú y foros de discusión

Cuando la investigación en curso versa sobre temas específicos, es necesario recurrir a especialistas. Este principio se replica en el Internet a través de las páginas de gurú.

Las páginas de gurú son sitios creados por investigadores generalmente, que realizan estudios sobre temas muy específicos y que comparten sus conocimientos a través de páginas web. Las páginas de profesores universitarios funcionan en muchos casos como páginas de gurú. ${ }^{5}$

Sin embargo, si lo que se desea es un contacto mucho más personalizado, del tipo pregunta-respuesta, podemos acceder a los foros de discusión. Estas herramientas se encuentran disponibles en muchas páginas web y permiten interactuar con personas que tienen intereses similares en todo el mundo, mediante la publicación de los temas bajo consulta y sus respectivas repuestas. ${ }^{6}$

\section{Páginas especializadas}

En todo país existen organismos gubernamentales y del sector privado que publican información estadística y estudios de investigación, siendo conocidas por la función que realizan o el sector al que representan.

Estas entidades son un punto de búsqueda directo cuando se necesita información relativa a su función (Ej. Superintendencia de Banca y Seguros: www.sbs.gob.pe al investigar sobre regulación bancaria y evolución del sistema financiero peruano) y tienen normalmente una sección de «sitios de interés» o "web útiles» desde los cuales podremos ingresar a instituciones similares en otros países del mundo, ampliando así nuestro horizonte de investigación.

Durante el proceso de investigación en Internet es sumamente importante identificar aquellos recursos o páginas web valiosas que nos puedan servir de referencia en la realización de futuras investigaciones. Este proceso permitirá identificar una serie de recursos útiles que nos ahorrarán tiempo de búsqueda y permitirán concentrar nuestros esfuerzos en el análisis de datos específicos orientados a nuestra rama de investigación.

Identificar estos recursos equivale a crear nuestra propia biblioteca de referencia en línea, la misma que debemos enriquecer mediante la búsqueda continua y el aprovechamiento de las bondades que el Internet pone a nuestro alcance.

\section{CONCLUSIÓN}

La investigación en línea supone un esfuerzo exhaustivo y una experiencia distinta cada vez, brindándonos la oportunidad de ser guiado a través de información relacionada y sirviendo como una biblioteca de referencia inagotable.

Los motores y meta motores de búsqueda, los catálogos temáticos, páginas de gurú, foros de discusión y páginas especializadas a los que hemos hecho referencia en el presente articulo no son sino un conjunto de herramientas que la revolución de tecnologías de 
información pone a nuestra disposición para potenciar el proceso de investigación científica.

El adecuado uso de estas herramientas nos permitirá extraer datos valiosos que deben servirnos como fuente para la generación de información mediante un análisis concienzudo y profundo. Sólo así estaremos seguros de haber logrado los objetivos de un verdadero proceso de investigación y de haber contribuido a la generación de conocimientos en la sociedad moderna: la sociedad de la información.

\section{BIBLIOGRAFÍA}

- BASCH, Reva. Investigación en Internet. Bogotá, Editorial Norma, 1998.

- REAl ACADEMIA ESPAÑOla. Diccionario de la Lengua Española. 2004, http://www.rae.es/. Lunes, 7 de junio de 2004, 20.35 horas.

- TERRONES NEGRETE, Eudoro. Diccionario de Investigación Científica, Lima, AFA Editores, 2001. 